\title{
Framing Entrepreneurship Education - Influencing Factors for Entrepreneurial Competency Learning at Universities in the Czech Republic
}

\author{
Michaela Slabová1,*, Ladislav Rolínek ${ }^{2}$ \\ South Bohemian University, Czech Republic \\ ${ }^{*}$ Corresponding author. Email: slabom02@ef.jcu.cz
}

\begin{abstract}
In the current dynamic development of the knowledge-based economy, which is characterized by an increased emphasis on the development of entrepreneurial competencies, the paper deals with possible approaches and a framework for supporting entrepreneurship education at universities. It is necessary to focus student education on active learning, creating challenges for students that would lead them to use thinking in the fields studied. Inclusion of this type of education requires action from the education side (reorientation between students and their teachers) and support from society. The higher importance in Czech Republic is given to conceptual system of entrepreneurship education. It is connected area based on education system, cooperation between schools and the private sector, training of business skills and emphasis is placed on the role of the teacher in this integrated process. This paper gives insight into new supporting and influencing factors for Entrepreneurial Competency Learning.
\end{abstract}

Keywords: Entrepreneurial Competency, Entrepreneurship Education, Active Learning.

\section{INDTRODUCTION}

The economic changes and societal challenges not only influence the skills and attitudes needed but have also shed new light on the role of universities in today's economics and society. Their role as leaders in education needs to be rethought. It may be argued in-depth that disciplinary and scientific expertise remains the cornerstone of a university education even though its enrichment with attitudes and skills, which aim to create new societal value and shaping of tomorrow's society, has become of the utmost importance.

In an attempt to address the shaping of the future, universities have fiercely invested in entrepreneurial programs, so the students can adapt to new skills that were not the point of focus in the curriculum and were neglected to a certain degree.-The role and the objective of the higher education sector still rest on the production and education of individuals who eventually develop themselves to be experts in a specialized domain and field. The World Economic Forum (2019) asserts that higher education is a "systemic failure" which does not equip graduates with the skills needed to solve 21st-century problems. The 2018 Gallup Report highlighted that a very small number of students after graduation have been given realistic expectations of employment prospects and enjoy their work [1].

The aim of the paper is to show the important frameworks and principles of support for business education. It can help also to evaluate the segments of development that will bring innovative approaches for the future development of this managerial and business discipline and thus support university graduates to start their business. Other specific goal is to encourage educational institutes to set up new opportunities and effective learning platform where the practical entrepreneurial skills can be trained and amplified. This modern support should go hand by hand with cooperation of other related fields. Here the emphasis is also put on the preparation of the business intention/plan, especially for small and medium-sized enterprises.

\section{ENTREPRENEURIAL EDUCATION ENVIRONMENT}

In the discussed topic of business and entrepreneurship, attention is increasingly turning towards Entrepreneurship Education. In addition to the popular phrase, this area is essentially a Mecca for today's young generation of potential entrepreneurs. A key role 
is played by a trainer or a teacher to get quality business education in the right form to students.

New methods and approaches in teaching that target critical thinking for better learning are becoming increasingly popular. Hamilton [2] states that it is necessary to transform from teaching to active learning, and also to transform from mere presentation of information by the teacher in class to the creation of challenges for students to guide them on how to use thinking in a given discipline. This shift is based on three new cognitive science findings: the use of analogous thinking; the best learning process takes place when there are clear processes, focused resources on this learning and also when we create our views on the findings; the existence of threshold concepts that define the discipline while also making it interesting and attractive for learners.

\subsection{Development of Entrepreneurial Competency}

If we look at the entrepreneurship education and its importance in the past, Jamieson [3] already proposed a three-categorical framework under which to organize business education:

\section{- First category - Business education}

Creation of awareness of the company as an economic entity with the aim to educate students about the aspects of business creation, and management from the theoretical point of view. Develop especially skills, attitudes and values suitable for a successful start, ownership, management of the company.

- The second category - Preparing individuals for the entrepreneurial career

Here a specific goal is sought, namely, to encourage participants to set up and run their own business. At this stage, the practical skills needed to set up and manage small businesses are taught and trained. Here the emphasis is also put on the preparation of the business intention/plan, especially for small and medium-sized enterprises.

- The third category - Managerial education, growth and future development of the company

This phase is intended for established entrepreneurs to maintain and develop their existing business. Emphasis is placed on management training, programs and specific courses for product development and marketing related to business development. Within the framework of this superstructure is also providing advice on the skills, knowledge, and attitudes of people, which also serves the personal growth and mental stability of the enterprising individual.

A key role is played by an educator or a teacher to get quality business education in the right form to students. The European Union has published a publication:
"Entrepreneurship Education: A Handbook for Educators", funded by the Competitiveness and Innovation Framework Program to promote the competitiveness of European businesses for the 20142020 period. This publication evokes that entrepreneurship education is more than just preparing to run a business. In the handbook, you can find some very interesting methods that develop students' entrepreneurial attitudes, skills and knowledge, or in other words competencies, which enable business ideas to be transformed into real actions. Entrepreneurial competencies that reflect reality require much more, especially active methods, to engage students in creativity and innovation, the student gaining these competencies, in particular by being able to apply practical learning in real-world conditions. This means that teaching subjects need to be designed to meet this purpose and much more so that, through the activation of entrepreneurship education, a new collaboration with businesses and professionals and the general public [4].

\subsection{Conceptual Model for Modern Entrepreneurship Education}

Entrepreneurship education in Europe is aimed primarily at economic and business schools. The key steps for further development are to expand business courses to other fields, such as scientific and technological departments, which are a hotbed of innovative ideas from which new companies and startups are created. Most students in Europe do not pursue entrepreneurs after graduation. In the United States, it's similar that people start a business only during the older stages of their careers [5].

China's rapidly developing business environment is also carrying a wave of innovation needs into the university education system. After the start of the intensive development of entrepreneurship education thanks to a pilot project of the Ministry of Education, new teaching methods are beginning to be developed at universities. From the early business competitions, through the education and training of lecturers and teachers themselves, the subjects in teaching are focused on the training of entrepreneurial skills with an emphasis on increasing the quality and diversity of educational styles [6].

An interesting insight into how entrepreneurship education shapes a comprehensive system is shown in Garba's Conceptual Model for Entrepreneurship Education. Scheme below highlights the importance and need for entrepreneurship education, acts also as a tool to alleviate socio-economic problems, such as youth unemployment in particular [7]. 


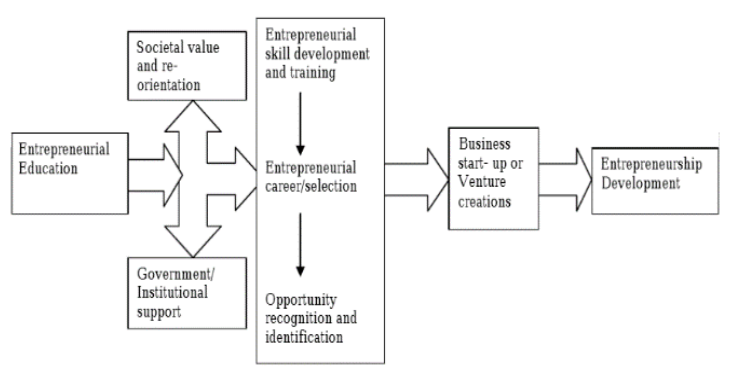

Figure 1 Garba - Conceptual Model for Entrepreneurship Education

\section{ENTREPRENEURSHIP EDUCATIONAL SYSTEM IN THE CZECH REPUBLIC}

Entrepreneurship education system in the Czech Republic is based on cooperation of schools and the private sector, the development of entrepreneurial skills and the role of teachers.

The support of entrepreneurship education includes the following recommendations:

\section{1) Education system}

Setting the education system up to provide motivation to acquire entrepreneurial skills for students with the ambition to start their own businesses, but also for those who want to work as employees.

2) Cooperation between schools and the private sector

The need to establish more and better cooperation between schools and companies, one of the main ones. The urgent need to link students and pupils with a real work environment with practical processes and habits. A creative method of establishing fictitious companies has proven successful in acquiring entrepreneurial skills, where students have the opportunity to learn practical and project skills related to company management in a safe environment simulating reality.

\section{3) Business skills}

A set of competencies and features that include creativity, invention, ability to realize ideas and risktaking, of which key competencies are language skills, financial literacy, and computer skills. The acquisition of entrepreneurial skills in education should work on the principle of an open list, which will be filled in over time. Initiatives such as the International Entrepreneurial Skills Pass or the Business School Initiative presented in the Year of Industry and Technical Education.

\section{4) The role of teachers}

The key role of teachers - good leadership of students, willingness to engage in activities to promote entrepreneurship beyond their work responsibilities within the school (also in the form of further education). Teachers' motivation to transfer knowledge and new teaching methods. Experts play an important role in the educational field of business. Creating conditions on campus that enable experts to be involved and able to pass on their experience to younger generations, also entails removing the current obstacles that prevent experts from teaching in schools and creating legislative conditions that would further encourage such cooperation.

The silver lining is that some other platforms and initiatives support entrepreneurship education and initiative for entrepreneurship. For example, the National Institute for Education has begun to deal with the area of "Business Education in Practice". This education aims at the development of entrepreneurial competencies of secondary school students. In cooperation with a private business club, a form of business education was created in the form of a "Business for Breakfast". The pedagogical goal of the project was to prepare pupils for professional life through familiarization with real companies, creative thinking of presentation of these companies, training of presentation and communication skills, presentation of members. In this connection, a webinar and a new digital portfolio for the development of entrepreneurship competencies are also being created [8].

Support for the development of business education in the Czech Republic is provided by a number of platforms, such as web-based signpost for the development of entrepreneurship - which provides 3 areas: Development tools (teaching materials and tools for anyone who wants to develop their entrepreneurship), In school (development of entrepreneurship teacher and student in school), Outside school (entrepreneurship in leisure and extracurricular activities) [9].

Important actors in the promotion of entrepreneurship education in the Czech environment, which also run national and centralized initiatives, are the Center of Fictitious Companies. Students across disciplines participate with their fictitious start-up companies offering products or services in the student competition Junior Achievement - Young Entrerprise Europe (JA$\mathrm{YE}$ ). This competition is organized once a year by one of the 40 European member states.

In addition to the above platforms, institutional support is also created to support the development of business entrepreneurship through the Operational Program 2014-2020, entitled "Research, Development and Education” (financed from European sources, and the structural and investment funds). The program is focused on entrepreneurship education in schools. This program sets entrepreneurship and the development of entrepreneurship competencies as one of the main priorities [10]. 


\section{CONCLUSION}

We live, more than ever before, in a knowledge-based economy, an economy where routine activities are increasingly automated or outsourced, and where creative tasks and innovation have become more prominent. Learning and unlearning is a vital capability required by an individual to swiftly adjust to a fast, changing economy. This capability is seemingly important as we also live in a society facing global challenges for which appropriate solutions have to be found. In this context, attitudes, skills and behaviours are needed that stimulate the pursuit of creative tasks and the addressing of complex problems in innovative ways. These attitudes, skills and behaviours can be called entrepreneurial, because they provide individuals with the willingness and ability to recognise and pursue opportunities for new value creation and problem solving in any setting. Entrepreneurship must therefore be understood as a multifaceted concept that includes the attitudes and skills to create new value in society, not (just) being a business owner or founder of a start-up.

Universities must play a role in developing these skills, which are required by changes in the economic environment. The paper presents some frameworks of entrepreneurship education.

\section{REFERENCES}

[1] M.E. Hansen, Higher education needs dusting off for the 21st century, 2018, https://www.weforum.org/agenda/2018/03/makehigher-education-skills-relevant-for-students/

[2] C. Hamilton, Critical Thinking for Better Learning: New Insights from Cognitive Science, Rowman \& Littlefield, 2016, pp. 54-56., ISBN: 978-1-47582778

[3] I. Jamieson, Schools and enterprise: in Watts, A.G. and Moran, P. (Eds), Education for Enterprise, CRAC, Ballinger, Cambridge, 1984, pp. 19-27.

[4] European Commission, \& Enterprise and Industry Directorate-General, Entrepreneurship Education: A Handbook for Pedagogy, Luxembourg: Publications Office, 2014, p.192

[5] E. K. Wilson, Entrepreneurship Education in Europe, Chapter 5, European Foundation for Entrepreneurship Research, OECD, 2008, pp. 5-6, ISBN- 9789264044098

[6] L. Weiming, L. Chunyan, Entrepreneurship Education in China, IntechOpen, 2015, DOI: $10.5772 / 59301$

[7] A. Garba, Refocusing Education System towards Entrepreneurship Development in Nigeria: a Tool for Poverty Eradication, European Journal of Social Sciences - Volume Number. 15, 2010, pp. 146-147

[8] Education for business in practice, 2013, http://www.nuv.cz/t/vychova-k-podnikani-v-praxi

[9] Methodical support to schools in the field of business, 2018, http://podnikavost.cz/veskole/metodicka-podpora/

[10] Entrepreneurship education in Czech Republic, 2016, https://www.schooleducationgateway.eu/download s/entrepreneurship/Czech_Republic_151022.pdf 